\title{
Do YouTube Vlogs influence Purchase Intention? The Mediation Role of Perceived Source Credibility
}

\author{
Ella Mittal ${ }^{*}$ and Navneet Kaur
}

Abstract

\section{INTRODUCTION}

This is the era of digitalization. The development of the internet and social media provided new platforms for businesses to build their strategies related to marketing to influence consumer's purchase intention (Yuksel, 2016). In the past, companies were considered as the sole creators of marketing messages or for disseminating any kind of product-related information. In current times, the scenario is changed with the emergence of digital media. The traditional one-way communication has been changed to two-way or multi-dimensional communication. The usage of digital media has gone beyond just a means of communication and information sharing. Social media plays a very important role in the marketing of consumer goods and services (Mangold \& Fauld, 2009). Various types of social media websites such as Instagram, Facebook, YouTube, and Blogs have now used a way to provide information which is known as eWOM, it is a marketing/advertising tool by marketers nowadays. These tools are known as social networking sites (SNS) (Bouhlel et al., 2010). These social media platforms serve in promoting the products or

\footnotetext{
Assistant Professor Ph.D, Department of Basic \& Applied Sciences, Punjabi University, Patiala Email: ellamittal12@gmail.com

** Research Scholar, University School of Applied Management, Punjabi University, Patiala Email: kaurn400@gmail.com (Corresponding Author)
} 
services either with the help of digital marketing or serve as a platform for viral marketing which is otherwise termed as eWOM as it transforms the traditional form of WOM from physical level to electronic medium. The marketers are vying to leverage Social Media as a marketing/advertising tool. There is an exponential growth in these SNS. By using social media platforms marketers can make content according to the needs of their audience; therefore it becomes important for researchers to study each platform of social media individually, with a great focus on the target audience (Lee \& Watkins, 2016). Purchase intention is a "Willingness of the consumer to purchase a product at a particular time or situation" and it predicts the actual behavior of customers (Lu et al., 2014). Social media is playing a great role among other factors in influencing purchase intention. This area is receiving growing attention in scholarly research.

This study focuses on YouTube, which is a very popular site for sharing videos that allow users to upload usergenerated content (UGC) that is viewed and shared by their viewers (Haven et al., 2007). User-generated content is media content created and shared by users (OECD, 2007). However, UGC is not confined to written reviews only. It is now very popular among users to create and share their videos. Previous studies suggest that usergenerated content shared on social media has a great influence on consumer's purchase intention. But very less research was conducted related to YouTube. Consumers share their views and information about the product. The person who creates records, uploads, and shares videos on YouTube is known as a vlogger. User-generated content on YouTube, in general, attract more viewers and subscribers compared to the content shared by official accounts of brands (Pixability, 2014) Along with this, vloggers are considered more knowledgeable as compared to traditional celebrities (Bianchi; 2016, Djafarova \& Rushworth, 2017, Fred, 2015). There are several studies related to various online platforms that influence consumers' purchase intentions such as social network sites (Bouhlel et. al., 2010), websites (Lee \& Watkins, 2016; Park et al., 2007), and blogs (Hsu \& Tsou, 2011; Hsu et al., 2013; Saxena, 2011), however very fewer studies are related to YouTube vlogs and most of them are related to beauty vlogs only and the previous studies were conducted on particular age group and the same type of respondent groups (Mir \& Rehman, 2013; Yuksel, 2016; Rahmi et al., 2017; Jannat, 2018). In India, a very less number of studies are found for YouTube vlogs, and most of the studies are related to electronic word of mouth overall (Bais et al., 2018; Nugraha \& Setyanto, 2018). The drawback of this research is a lower number of published articles about YouTube vlogs. To the best of our knowledge, no study has examined the influence of YouTube vlogs on Indian consumers' purchase intentions and the mediating role of source credibility. This study is related to analyzing the influence of YouTube vlogs on the purchase intention of consumers' in the presence of source credibility as a mediator and previous experience of consumers as moderator. Therefore this study aims to answer the following research questions which are drawn from previous studies.

1. Do YouTube vlogs influence the purchase intention of consumers?

2. What kind of videos (vlogs) do users watch most of the time?

3. Does the perception of consumers about trustworthiness, expertise, and attractiveness of YouTube vloggers mediate the influence of vlogs (Source of information) on consumers' purchase intentions?

4. Does the previous experience of consumers in using the product have a moderation effect on the influence of vlogs on consumers' purchase intention?

\section{Background and hypothesis development}

\section{Purchase Intention}

According to the theory of reasoned action (TRA), any person's subjective probability to perform a specific action 
is known as behavioral intention (Davis, 1986). This theory also suggests that by referring to information from or normative practices of a group and peers, an individual may develop beliefs. Consequently, these beliefs will influence the behavioral intention of an individual. In various studies of consumer purchase behavior, a consumer's intention to buy a product in the future is known as purchase intention. It can be used to predict real consumer purchase behavior (Hsu \& Tsou, 2011; Saxena, 2011); this is the reason that it has attracted a lot of interest in researches nowadays. Bandura (1963) gave the social learning theory that provides a theoretical framework for academic research in the field of communication and advertising. This theory provides the idea of socialization agents that can predict the consumption behavior of a consumer (King \& Multon, 1996; Martin \& Bush, 2000). This theory was adopted by many researchers to understand the influence of various social agents on the consumption behavior of consumers. Makgosa (2010) used social learning theory and revealed that social media influencers can shape the purchase behavior of a consumer with the use of social media. In the context of this study, social learning theory suggests that information and reviews given by social media agents influence the purchase intentions of a consumer. Some studies show the influence of eWOM information on the purchase intention of consumers (See-To \& Ho, 2014; Wang et al., 2012). Previous research suggests that information shared on social media has more influence on consumers' purchase intention compared to the officially created promotional content.

\section{Producer Generated Content versus User Generated Content}

Producer generated content (PGC) is a message or content given by or on the behalf of the producer through their official sites in the form of advertisements about their product or service. It includes third-party endorsement (celebrities), warranties, and money-back guarantees (Euijin \& Tadisina, 2007). Traditional celebrities' endorsement was considered impactful as they had a great influence on consumers' mind-set. However, in recent years of digitalization, there has been a rise in a new type of social media celebrities. These celebrities are from the general public. They are the actual users of products and services (Chahal, 2016). Social media is a platform where users can generate their content in the form of written reviews, blogs, video vlogs, etc. This is known as usergenerated content (Mir \& Rehman, 2013). User-generated content may have a stronger influence on consumers as compared to producer generated content. However, research has been conducted on written reviews, such as blogs, while user-generated content is not limited to written content only (Hautz et al., 2014). User-generated content attracts more viewers than the content uploaded by official accounts of producers (Pixability, 2014; Wiley, 2014; Camahort, 2016). Advancement in technology and social media is providing many platforms for consumers to post photos and videos to provide their reviews. YouTube is a video sharing site where users upload their videos as vlogs for giving their reviews. These vloggers are ordinary consumers who create, upload, and share videos about products and services. Hsu et al. (2013) stated that YouTube vlog is one of the popular eWOM platforms nowadays, which are considered by online users as a highly credible source among all sources in different media. Through watching YouTube vlogs frequently, watchers become familiar with vloggers and the content they provide. This study investigates the influence of information given by YouTube vloggers on consumers' purchase intentions.

H1: YouTube vloggers (Source of Information) has a strong influence on consumer purchase intention

\section{Perceived Source Credibility}

Source credibility theory states that a message is more likely to persuade the consumers and their purchase intentions when the source of a message is considered to be credible (Wilson \& Sherrell, 1993). In simple terms credibility of a source is defined as the positive attitude of the source that influences the receiver to accept a 
message (Ohanian, 1990). The concept of credibility is based on the judgment of the reader (Freeman \& Spyridakis, 2004) and previous studies showed that credibility depends on the personal perception of receivers (Johnson et al., 2008). Previous research has concluded the three key dimensions of credibility that are trustworthiness, expertise, and attractiveness which make a source be perceived as credible to message recipients. In general, perceived credibility is the trust dimension that influences the behavior of a consumer positively or negatively. The influence of credibility applies to the digital environment also (Cheung et al., 2009). In a digital environment, credibility is considered as the credibility of the content generator (Burgess et al., 2009).

The trustworthiness of the source is how much he/she provides true, sincere, honest, and fair information (Ohanian, 1991). A source is considered trustworthy when the message shared by him is very effective to influence the attitude of an individual than an advertisement shared by official celebrities hired by companies of that particular product or service (Ohanian, 1990; Pornpirakpan, 2003; Chu \& Kamal, 2008). They further explain that vloggers who argue against self-interest are considered to be more trustworthy than those who pay great attention to their self-interest. Furthermore, vloggers are perceived as more identical to consumers than celebrities (Bianchi, 2016; Djafarova \& Rusworth, 2017).

\section{H2: YouTube vloggers are perceived as trustworthy}

The expertise of a vlogger refers to the level of his/her ability and capability to make valid assertions (McCroskey, 1966; Pornpitakpan, 2003). A person is perceived as an expert when he is seen as having great knowledge and experience about the product or service and he supports his claims in a message (Ohanian, 1991; Luthie, 2004). Further, it is argued that YouTube vloggers are considered more expert than celebrities as they would look more knowledgeable since they make tutorial videos on how they use the product personally (Rahmi et al., 2017).

\section{H3: YouTube vloggers are perceived as having expertise}

The attractiveness of the source is related to his/her physical appearance. Previous research suggests that attractiveness can play a great role in making a preliminary judgment about a source (Baker \& Churchill, 1977; Kahle \& Homer, 1985). They further explained that an attractive communicator has a great influence on consumers in persuasion intentions than an unattractive communicator. Besides, it is said that the attractiveness of a source has a positive impact on influencing the consumers' purchase intention (Joseph, 1982).

\section{H4: YouTube vloggers are perceived as attractive}

Source credibility has been identified as one of the most important factors in influencing consumers' purchase intention. Various studies suggested that perceptions of the consumer about perceived source credibility i.e. perceived trustworthiness; perceived expertise and perceived attractiveness of the source of information about a product influence their purchase intention (Ohanian, 1991). In their study, Ananda \& Wandebori (2016) found that the perceived credibility of vloggers positively predicted consumers' positive attitude and purchase intention. For instance, Djafarova \& Rusworth (2017) and Hill et al. (2017) investigated in their studies that both YouTube vloggers and traditional celebrities have an almost equal influence on the purchase intention of consumers; however, consumers perceive YouTube vloggers more credible than celebrities. Thus for checking the mediation role of perceived source credibility in influencing the purchase intention of consumers, the following hypotheses were formulated:

H5: Consumers' perception of vloggers' trustworthiness mediated the influence of vlogs on consumers' purchase intention 
H6: Consumers' perception of vloggers' expertise mediates the influence of vlogs on consumers' purchase intention

H7: Consumers' perception of vloggers' attractiveness mediates the influence of vlogs on consumers' purchase intention

\section{Previous Experience}

There are some studies which investigated the interaction between previous experience of consumers in using the product and the source of information in influencing purchase intention of consumer (Schiffman \& Wisenblit, 2015). It was found that advertising has very less influence on consumers who have used the product than among those with little or no experience at all (Levin \& Gaeth, 1988). Contrary to these results, some studies suggested that previous experience of the consumer with the product reinforced the persuasiveness of commercial advertisement, which affected the intention of consumers to repurchase the product (Deighton \& Schindler, 1988; Petrick, 2002). In the present study, previous experience in using the product was taken as a moderator that may affect the influence of YouTube vloggers on consumers' purchase intention. Therefore, the following hypothesis is also tested in this study:

H8: Consumers' previous experience in using the product moderates the influence of vlogs on consumers' purchase intention.

\section{CONCEPTUAL MODEL}

The conceptual model of this study is given in figure 1.

Figure 1.

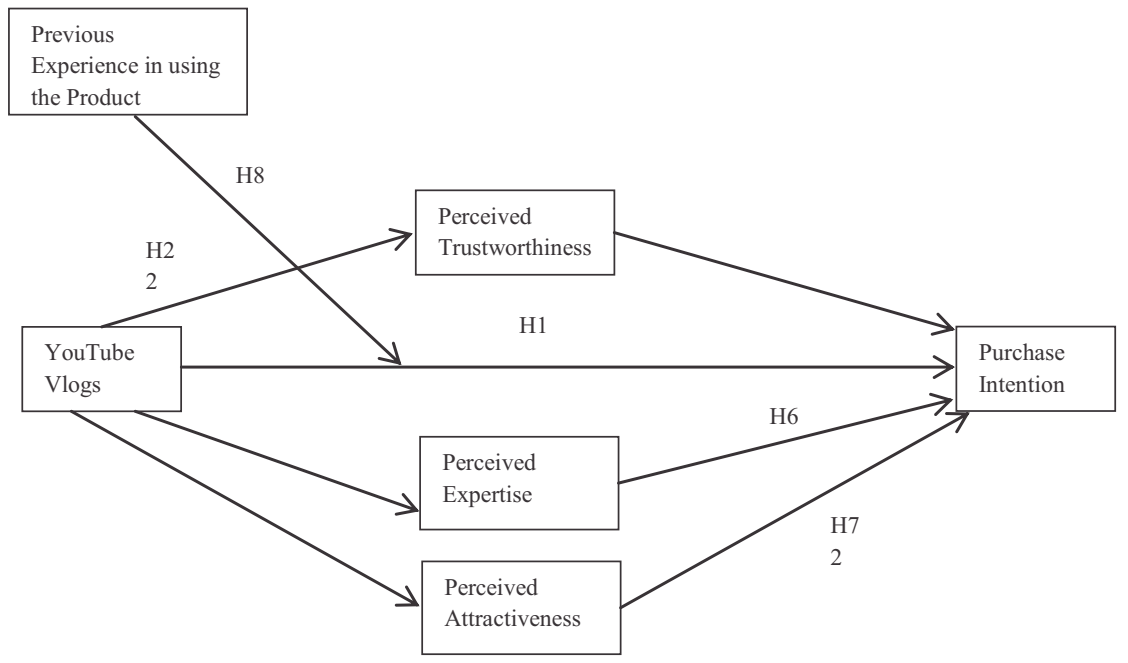

\section{Methods}

\section{Research Participants}

This study used a quantitative approach by conducting an online survey of Indian female YouTube users aged 18 to 55, which included students, working, and non-working females. Females were selected because they make up the 
majority of consumers who seek information about beauty products; apparel and accessories on social media as well as YouTube vlogs (Pixability, 2015). Females are also targeted by the cosmetic and fashion industries. The study was conducted in Punjab and Chandigarh Tricity. A total of 200 questionnaires were distributed through the social networks from which 170 responses were obtained. While analyzing the data, 20 questionnaires got discarded because of missing and invalid responses. Therefore, a total of 150 questionnaires were analyzed for results. According to the rule of thumb for sample size needed for analyzing a model, a quite small sample size can be used but usually, $\mathrm{N}=100-150$ is considered the minimum sample size for analysing a model (Tinsley \& Tinsley, 1987; Anderson \& Gerbing, 1988; Ding et al., 1995; Tabachnick \& Fidell, 2001). The research data were obtained through a close-ended questionnaire using a convenience sampling technique.

\section{Questionnaire and Measurements}

This study measured Four variables based on several previous studies; Vlogs (Source of information), perceived source credibility (perceived trustworthiness, perceived expertise, and perceived attractiveness), previous experience, and purchase intention. The questionnaire was prepared based on the following scales:

YouTube Vlogs (source of information)

A source of information about YouTube vlogs was measured by using the four dimensions: relevance, timeliness, accuracy, and comprehensiveness identified in previous studies (Cheung et al., 2009; Erkan \& Evans, 2016; Tang, 2017). These dimensions were measured by using 8 statements on 5 points Likert scale ( $1=$ strongly disagree up to $5=$ strongly agree).

Purchase Intention

Purchase intentions of consumer construct items were adapted from Taylor \& Baker (1994), Coyle \& Thorson (2001), and Hill et al. (2017). It was measured using a 5 items scale. An example of the item is "It is very likely that I will buy the product". Responses were measured using 5 points Likert scale $(1=$ strongly disagree up to $5=$ strongly agree). Higher the score indicated stronger purchase intention.

\section{Perceived Source Credibility}

Perceived source credibility (Perceived Trustworthiness, Perceived Expertise, Perceived Attractiveness) of vloggers measured with items adapted from scale given by Ohanian (1990). It was measured using 5 items of each dimension with 5 points semantic scale.

\section{Previous Experience}

In the present study, individuals' previous experience in using the product was taken as a moderating variable, which was measured by asking a direct question from the respondents i.e. "If you had already used the products then whether you get influenced by YouTube vloggers to buy the same products again?". Responses were coded into two categories: "1" to those who had experience in using the product and will buy the product again and " 0 " to those who had no experience in using the product and will buy the product. 


\section{Data Analysis Technique}

The collected was coded and analyzed using SPSS version 23. In this study, one-way ANOVA was used for analyzing demographic profiles, the reliability of scales was analyzed using Cronbach's a in the study. Hypotheses were tested using regression analyses, Model 5 of PROCESS version 3.4 for IBM SPSS version 23 with 5000 bootstraps at a 95\% confidence level (Hayes, 2013).

\section{RESEARCH RESULTS}

\section{Demographics and Descriptive Statistics}

It is essential to assess the normality of data before any statistical analysis. Otherwise, we might draw erroneous inferences and wrong conclusions. To check the normality of data in this study, two descriptive statistic functions are used: Skewness and Kurtosis. As shown in Table 1 all the values of skewness are between -.5 and .5 . Therefore the data are fairly skewed. The values of kurtosis are also acceptable and statistically significant according to the greater rule of $Z$ value (kurtosis statistics/std. error $=$ value) the value comes between $\mathrm{z}$ value -1.96 and 1.96 (Cramer \& Howitt, 2004).

The description of the sample shows the aspect of age, employment, income, and qualification. The majority of respondents were from the age group of $15-25$ and $25-35$ i.e. $35 \%$ and $33 \%$ respectively, $21 \%$ from the $35-45$ age group and $11 \%$ from the age group $45-55$. In the aspect of employment, $53 \%$ of respondents were working and $16 \%$ were non-working, there were $30 \%$ of students. In the aspect of income, the majority of the respondents were having monthly income less than $20 \mathrm{~K}$ i.e. $34 \%$, the rest were categorized as $25 \%$ in $30 \mathrm{~K}-40 \mathrm{~K}, 21 \%$ in $20 \mathrm{~K}-30 \mathrm{~K}$, $11 \%$ in $40 \mathrm{~K}-50 \mathrm{~K}$, and $9 \%$ in $50 \mathrm{~K}$. When talking about qualifications, the majority of the respondents were postgraduate (39\%) and graduate (37\%), 12\% completed secondary school, $8 \%$ were doctorates and only $3 \%$ of respondents completed high school. The majority of the respondents (96\%) were regular YouTube users, only $4 \%$ of respondents were not active on YouTube. $83 \%$ of respondents agreed that they watch user-generated content frequently and the rest $17 \%$ were not frequent watchers of user-generated content on YouTube. The effect of demographic variables is shown in Table 2. The influence of age, employment, income, and qualification were analyzed using one way ANOVA. A significant difference was found in trustworthiness in terms of age. There was also a significant variance in the variable purchase intention in terms of age, employment, and income.

Table 1: Descriptive Statistics

\begin{tabular}{|l|l|l|l|l|l|l|}
\hline & Mean & $\begin{array}{l}\text { Std. } \\
\text { Deviation }\end{array}$ & \multicolumn{2}{|l|}{ Skewness } & \multicolumn{2}{l|}{} \\
\hline & Statistic & Statistic & Statistic & $\begin{array}{l}\text { Std. } \\
\text { Error }\end{array}$ & Statistic & $\begin{array}{l}\text { Std. } \\
\text { Error }\end{array}$ \\
\hline YouTube Vlogs & 3.72 & .54 & -.16 & .198 & -.312 & .394 \\
\hline Trustworthiness & 3.64 & .61 & .04 & .198 & -.326 & .394 \\
\hline Attractiveness & 3.60 & .58 & -.13 & .198 & .145 & .394 \\
\hline Expertise & 3.84 & .70 & -.49 & .198 & -.045 & .394 \\
\hline $\begin{array}{l}\text { Purchase } \\
\text { Intentions }\end{array}$ & 3.71 & .63 & -.50 & .198 & .396 & .394 \\
\hline
\end{tabular}

(Source: Primary Data) 
Table 2: Effect of Demographic variables on youtube Vlogs, Perceived Source credibility (Trustworthiness, Attractiveness, and Expertise) and Consumers' Purchase Intention

\begin{tabular}{|l|l|l|l|l|l|l|l|l|}
\hline Variables & \multicolumn{2}{l}{ Age } & \multicolumn{2}{l|}{ Employment } & \multicolumn{2}{l|}{ Income } & \multicolumn{2}{l|}{ Qualification } \\
\hline & F & P & F & $\mathbf{p}$ & $\mathbf{F}$ & $\mathbf{p}$ & $\mathbf{F}$ & $\mathbf{P}$ \\
\hline YouTube Vlog s & .25 & .06 & .25 & .77 & 2.19 & .07 & 2.22 & .06 \\
\hline Trustworthiness & 3.33 & $.02^{*}$ & .36 & .69 & 1.75 & .14 & 2.27 & .06 \\
\hline Expertise & 2.43 & .06 & .24 & .78 & 2.39 & .05 & 1.76 & .14 \\
\hline Attractiveness & .71 & .54 & .56 & .57 & 1.02 & .39 & 1.33 & .26 \\
\hline Purchase Intention & 3.76 & $.01^{*}$ & 3.46 & $.03^{*}$ & 2.70 & $.03^{*}$ & 1.16 & .33 \\
\hline
\end{tabular}

(Source: Primary Data)

Table 3: Cross-tabulation analysis of User Generated Content (vlogs) responses based on age groups of Respondents

\begin{tabular}{|l|l|l|l|l|}
\hline \multirow{2}{*}{ Age } & \multicolumn{2}{|l|}{ User-Generated Content ( Vlogs) } & \multirow{2}{*}{ Total } \\
\cline { 2 - 4 } & Beauty & Apparels & Accessories & \\
\hline $\mathbf{1 5 - 2 5}$ & 31 & 15 & 21 & 50 \\
\hline $\mathbf{2 5 - 3 5}$ & 35 & 20 & 36 & 52 \\
\hline $\mathbf{3 5 - 4 5}$ & 20 & 18 & 19 & 32 \\
\hline $\mathbf{4 5 - 5 5}$ & 6 & 5 & 12 & 16 \\
\hline Total & 92 & 58 & 88 & 150 \\
\hline
\end{tabular}

(Source: Primary Data)

Table 3 shows that the respondents from the 15-25 age groups are more prone to beauty-related YouTube vlogs. There were a total of 50 respondents from this age group and 31 out of this mostly watch beauty related videos. Further, the respondents from the 25-35 age groups watch beauty and accessories related vlogs most of the time. The response of respondents from the 35-45 age groups was almost equal for all kinds of vlogs. There were only 16 respondents from the 45-55 age group and they used to watch accessories related to YouTube vlogs most of the time. 
Table 4: Cross-tabulation analysis of User Generated Content (vlogs) responses based on age groups of Respondent

\begin{tabular}{|l|l|l|l|l|}
\hline \multirow{2}{*}{ Employment } & \multicolumn{2}{|l|}{ User -Generated Content ( Vlogs) } & \multirow{2}{*}{ Total } \\
\cline { 2 - 4 } & Beauty & Apparels & Accessories & \\
\hline Working & 46 & 30 & 52 & 80 \\
\hline Non-Working & 15 & 10 & 16 & 24 \\
\hline Students & 35 & 18 & 20 & 46 \\
\hline Total & 96 & 58 & 88 & 150 \\
\hline
\end{tabular}

(Source: Primary Data)

Table 4 describes the multiple responses based on the employment profiles of respondents. There were a total of 80 working respondents and 52 out of them watches YouTube vlogs related to accessories and responses of nonworking respondents were almost the same for beauty-related vlogs and accessories-related vlogs. Further, the response given by 46 students shows that students mostly watch beauty-related vlogs.

\section{RELIABILITY}

The present study adopted Cronbach's a coefficient to measure the reliability of the questionnaire. The overall reliability analysis revealed a Cronbach's a of .92, which is above .70 . The Cronbach's a of vlogs (source of information), trustworthiness and attractiveness were .83, the Cronbach's a of expertise was .89. The Psychometric assessment of purchase intention showed reliability Cronbach's a coefficient of .86, showing the good internal consistency of the research questionnaire.

Table 5: Direct Effect of YouTube vlogs on Consumers' Purchase Intentions and Perceived Source Credibility (Trustworthiness, Attractiveness, and Expertise)

\begin{tabular}{|lc|l|l|l|l|l|l|}
\hline Variables & $\mathbf{b}$ & $\mathbf{s e}$ & $\mathbf{t}$ & $\mathbf{p}$ & $\mathbf{L L C I}$ & $\mathbf{U L C I}$ \\
\hline \multicolumn{2}{|l|}{ Purchase Intentions (H1) } & .68 & .07 & 11.48 & .00 & .65 & .92 \\
\hline Trustworthiness & $\mathbf{( H 2 )}$ & .89 & .04 & 24.56 & .00 & .92 & 1.07 \\
\hline Expertise & $\mathbf{H 3})$ & .79 & .06 & 16.05 & .00 & .89 & 1.14 \\
\hline Attractiveness & $\mathbf{H 4})$ & .63 & .07 & 9.95 & .00 & .54 & .83 \\
\hline
\end{tabular}

(Source: Primary Data)

Note: $b=$ coefficient, $s e=$ standard error, $t=t-v a l u e, ~ p=$ significance level

LLCI= Lower limit confidence interval, $\mathrm{ULCI}=$ Upper limit confidence interval

In table 5, Data analysis shows a direct influence of YouTube vlogs on the purchase intention of consumers (H1) $(\mathrm{b}=0.68, \mathrm{se}=.07, \mathrm{p}=.00)$. This result supports the $\mathrm{H} 1$ and revealed that the influence of video source is significantly 
predicting consumers' purchase intention. Similarly, the analysis showed that YouTube vloggers are perceived Trustworthy $(\mathrm{H} 2)(\mathrm{b}=.89, \mathrm{se}=.04, \mathrm{p}=.00)$, Expertise $(\mathrm{H} 2)(\mathrm{b}=.79, \mathrm{se}=.06, \mathrm{p}=.00)$ and Attractive $(\mathrm{H} 3)(\mathrm{b}=.63$, $\mathrm{se}=.07, \mathrm{p}=.00$ ) by consumers. This suggests that vlogs influence consumers' purchase intention and it also affects consumers' perception towards perceived source credibility (Trustworthiness, Expertise, and Attractiveness). Therefore, the results supported $\mathrm{H} 1, \mathrm{H} 2, \mathrm{H} 3$, and $\mathrm{H} 4$.

Table 6: Results of Mediation and Moderation analysis when the outcome variable is consumers' purchase intentions

\begin{tabular}{|c|c|c|c|c|c|c|}
\hline Variables & $\mathbf{b}$ & se & $\mathbf{t}$ & $\mathbf{p}$ & LLCI & ULCI \\
\hline Constant & 1.27 & .56 & 2.27 & .02 & .16 & 2.38 \\
\hline Trustworthiness & $\begin{array}{l}.09 \\
-.09\end{array}$ & .15 & -.59 & .55 & -.40 & .21 \\
\hline Attractiveness & .01 & .08 & .15 & .87 & -.15 & .17 \\
\hline Expertise & .19 & .09 & 2.02 & .04 & .00 & .38 \\
\hline YouTube Vlogs & .45 & .28 & 1.63 & .10 & -.09 & 1.01 \\
\hline Previous Experience & -.22 & .63 & -.34 & .72 & -1.4 .7 & 1.03 \\
\hline Interaction & .15 & .18 & .84 & .40 & -.21 & .51 \\
\hline \multicolumn{7}{|l|}{ Indirect effect } \\
\hline Variables & Effect & Boot SE & Boot LLCI & Boot ULCI & & \\
\hline Total Indirect effect & .1124 & .3652 & -.6606 & .7804 & & \\
\hline Trustworthiness (H5) & -.0925 & .2178 & -.5350 & .3310 & & \\
\hline Expertise (H6) & .1958 & .1313 & .0917 & .4262 & & \\
\hline Attractiveness (H7) & .0090 & .0691 & -.1410 & .1346 & & \\
\hline
\end{tabular}

(Source: Primary Data)

Note: $b=$ coefficient, $s e=$ standard error, $t=t$-value, $\mathrm{p}=$ significance level

LLCI $=$ Lower limit confidence interval, ULCI $=$ Upper limit confidence interval

Table 6 shows the mediation role of trustworthiness, expertise, and attractiveness of YouTube vloggers between vlogs (source of information) and consumers' purchase intention. The result shows that there was no significant effect of mediating variables: trustworthiness $(\mathrm{b}=-.09, \mathrm{se}=.15, \mathrm{p}=.55)$ and attractiveness $(\mathrm{b}=.01, \mathrm{se}=.08, \mathrm{p}=$ $.87)$. However expertise $(\mathrm{b}=.19, \mathrm{se}=.09, \mathrm{p}=.04)$ significantly mediated the relationship between vlogs and purchase intentions. This suggests that perceived source credibility (trustworthiness and attractiveness) does not play the role of mediation and thus does not affect the relationship of vlogs (source of information) and consumers' purchase intention but expertise acts as a mediator. Therefore, $\mathrm{H} 5$ and $\mathrm{H} 7$ are not supported. However, results supported H6. Results also showed that there was insignificant indirect effect of trustworthiness ab=-.0925, CI ($.5350, .3310)$ and attractiveness $a b=-.0090$, CI $(-.1410, .1346)$ on purchase intentions. However, there was a significant indirect effect of expertise $a b=.1958$, CI $(.0917, .4262)$ on purchase intentions. Further, it shows the 
moderating effect of previous experience of consumers on YouTube vloggers' influence on the purchase intention of consumers in the presence of mediating variables. The result shows that vlogs (source of information) do not affect consumers' purchase intentions in the presence of mediating variables trustworthiness, expertise, and attractiveness and moderating variable previous experience of products. Consumers' previous experience does not moderate the consumers' purchase intention with the influence of YouTube vlogs. So it can be concluded from Table 6 that $\mathrm{H} 8$ does not support $(\mathrm{b}=-.22$, $\mathrm{se}=.63, \mathrm{p}=.72$ ). It is also shown in fig. 2 . Further analysis showed that consumers who watch YouTube vlogs got more influenced to purchase the product than those who don't watch vlogs $(\mathrm{b}=.61, \mathrm{se}=.25, \mathrm{p}=.01)$. Probing the conditional effect in Table 7, it can be seen that results of the conditional effect of YouTube vlogs on purchase intentions vary among non-users $(b=.44, p=.10$, CIs -.09, 1.10) and experienced users $(\mathrm{b}=.61, \mathrm{p}=.01$, CIs $.11,1.10)$. The slope test of interaction between experience and vlogs are also shown in figure 2 . The total mediation and moderation effect is shown in figure 3.

Table 7: Conditional Direct Effect on Source of Information (Vlogs) on Purchase Intention Moderated by the Experience of Using the Product

\begin{tabular}{|l|l|l|l|l|l|l|}
\hline Conditional direct effect(s) of X on Y at values of the moderator(s): \\
\hline Variables & b & se & $\mathbf{t}$ & $\mathbf{p}$ & LLCI & ULCI \\
\hline Non -Users & .45 & .28 & 1.63 & .10 & -.09 & 1.10 \\
\hline Experienced Users & .61 & .25 & 2.44 & .01 & .11 & 1.10 \\
\hline
\end{tabular}

(Source: Primary Data)

Note: $\mathrm{b}=$ coefficient, $\mathrm{se}=$ standard error, $\mathrm{t}=\mathrm{t}$-value, $\mathrm{p}=$ significance level

LLCI $=$ Lower limit confidence interval, ULCI $=$ Upper limit confidence interval

Figure 2: Conditional Direct Effect of the YouTube Vlogs (Information Source) through Perceived Source Credibility as a Mediation and Experience Using the Product as Moderation.

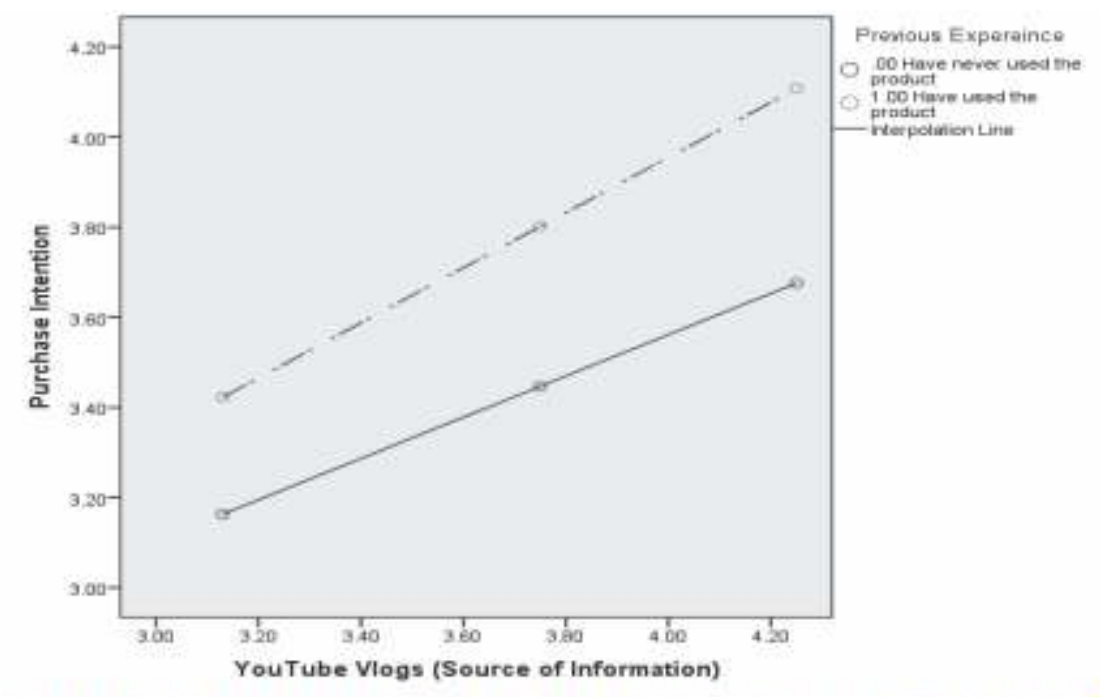


Figure 3: Mediation and Moderation Effect

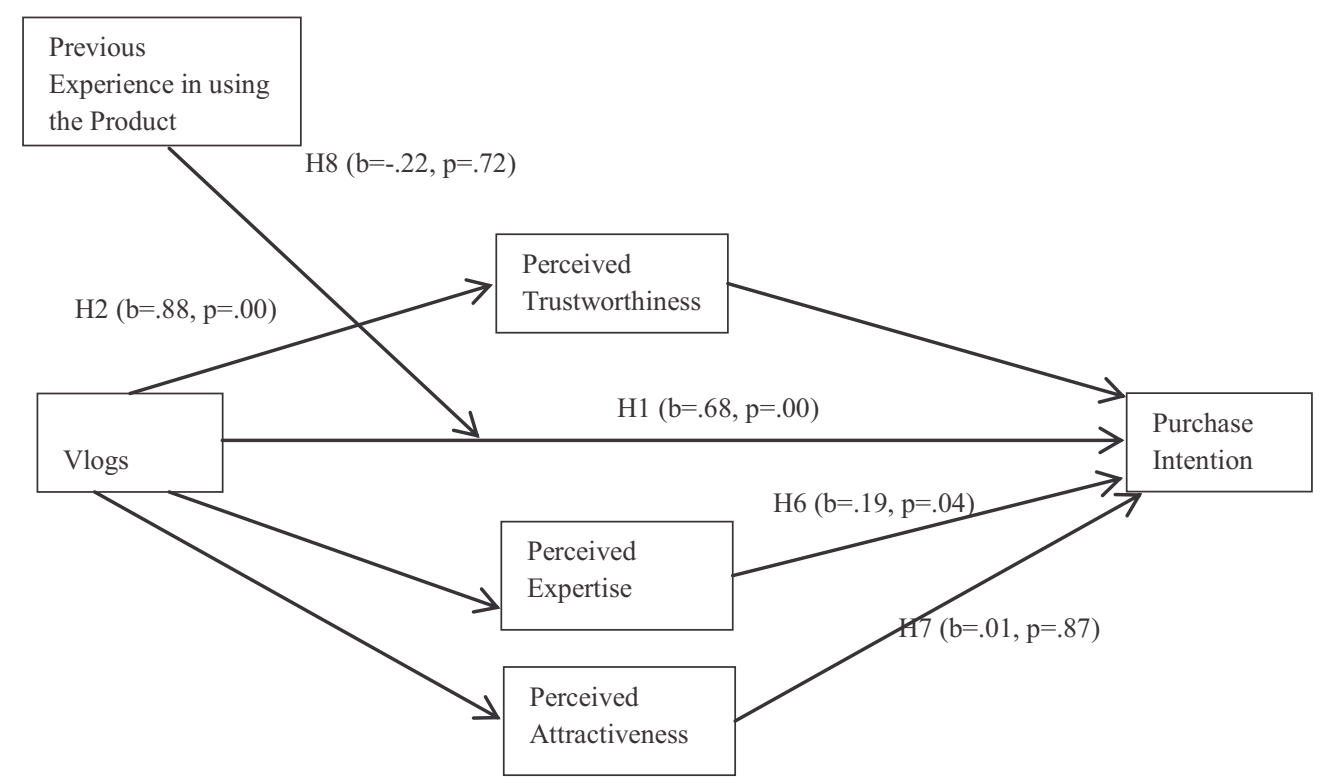

\section{DISCUSSION}

YouTube as an appropriate platform of eWOM has not been explored although various platforms have consolidated its position as an effective tool to lead consumers' purchase intentions. The purpose of this study was to analyze the influence of YouTube vlogs on consumers' purchase intention with the mediating role of trustworthiness, expertise, and attractiveness. Additionally, the moderating role of consumers' previous experience related to the product was also analyzed. Further, this study also found the popularity of YouTube vlogs and user-generated content among consumers. The results found that the majority of consumers from every age group regularly watch YouTube videos and especially the user-generated content means the videos uploaded by digital celebrities who are known as YouTube vloggers. Respondents were asked about the content which they watch most of the time out of 3 kinds of vlogs: Beauty related vlogs, Apparels related vlogs, and Accessories related vlogs. The results showed that they mostly watch the beauty-related vlogs and after that vlogs related to accessories.

The result of this study shows a significant effect of YouTube vlogs on consumers' purchase intention. It can be said that videos made by YouTube vloggers are very influential in increasing the purchase intentions of consumers. Consumers pay great attention to user-generated content than producer generated content; vlogs are more effective than online official advertisements. The result supports the studies performed by Djafarova dan Rushworth (2017) which showed that information given by YouTube vloggers is considered more influential than traditional celebrities and this study also shows the same results that vloggers play a great role in influencing the purchase decision of consumers. The other researches are done by Erkan \& Evans (2016) and Jin et al. (2009) also support the results of this study. Along with this, vloggers are perceived as trustworthy, expertise, and attractive by the respondents. Vloggers are considered to be trustworthy about their reviews, expert in their area, and physically attractive. This result is consistent with the existing literature on consumers' perception of YouTube vloggers that consumers' purchase intentions are strongly linked to eWOM based on trust and creditability of digital celebrities (vloggers) about the products' reviews given by them on the social media platform. Consumers do follow them as the non-branded YouTubers possess high rated expertise and trustworthiness (Bianchi, 2016; 
Djafarova \& Rushworth, 2017; Fred, 2015; Wiley, 2014). The results of the current study are also consistent with these previous studies concerning the influence of YouTube vloggers on consumers' purchase intentions. However, most of the previous studies analyzed only two variables of perceived source credibility (expertise and trustworthiness) but this study analyzed the one more important variable of source credibility i.e. attractiveness of YouTube vloggers, and it was found that attractiveness of YouTube vlogger also plays a great role in influencing the purchase intentions of consumer same as expertise and trustworthiness of vloggers.

This study also investigated the mediating role of YouTube vloggers' trustworthiness, expertise, and attractiveness between vlogs (source of information) and consumers' purchase intention. The result shows that consumers' perception of vloggers' trustworthiness, expertise, and attractiveness do not significantly mediate the relationship between consumers' purchase intention and source of information. YouTube vloggers are perceived as trustworthy, expert, and attractive by consumers but their credibility doesn't play the role of mediating factor in influencing the purchase intention of consumers. This result is consistent with the previous study of Rahmi et al. (2017) but inconsistent with other studies of Hautz et al. (2014); Ohanian (1990); Pornpitakpan (2003), which found the consumers' perception about trustworthiness, expertise, and attractiveness mediated the relationship between vlogs (source of information) and consumers' purchase intentions. Along with this, the study also investigated the moderating role of the previous experience of consumers. The majority of consumers agreed to purchase the products by getting influenced by YouTube vloggers which they have already used. However, consumers' previous experience did not significantly affect the relationship between vlogs (source of information) and consumers' purchase intentions as moderator. It was not found to moderate the influence of YouTube vloggers on the purchase intentions of consumers. This result was inconsistent with previous research by Deighton $\&$ Schindler (1988), Petrick (2002), Rahmi et al. (2017), which found a significant effect of previous individual experience related to product and interaction between source of information and experience that can lead to persuasion.

\section{CONCLUSION}

The results of this study showed in present times YouTube is very much popular among all age groups for its usergenerated content. Consumers are regular YouTube users. Therefore, the results showed that there was a significant effect of YouTube vlogs on consumers' purchase intention. It describes that there is a great influence of YouTube vloggers on the purchase intention of consumers. YouTube vloggers were perceived as trustworthy, expertise, and attractive by consumers. However, consumers' perception of trust, expertise, and attractiveness of vloggers did not mediate the relationship between vlogs and consumers' purchase intention. This indicates that there was no influence on consumers' perception of the trustworthiness, expertise, and attractiveness of YouTube vloggers and they do not affect the consumers' purchase intentions as mediators. Furthermore, there was no moderation effect of consumers' previous experience about the related product between exposure to vlogs and purchase intention of consumers.

\section{IMPLICATIONS}

Practical Implications: From a practical and managerial implication perspective, the results of this study suggest that marketers can utilize online advertising through YouTube vlogs for their business. The study found that YouTube vloggers are considered trustworthy, experts for the information they do provide and their attractiveness also matters for consumers. Consumers, these days are very much interested in vlogs and user-generated content. For this reason, brands and companies need to deliver their marketing messages through ordinary users. The 
companies can use this source to provide information to their target audience. According to the results of this study, young consumers pay great attention to beauty and accessories related videos. YouTube serves as a powerful platform for electronic word of mouth in the cosmetic industry because consumers tend to watch beautyrelated videos. Therefore, in this study's context, this platform can be effectively used by marketers to retain existing consumers and to recruit new consumers. Brands can collaborate with YouTube vloggers because most of the females watch their reviews before buying the products.

Theoretical Implications: From a theoretical implication perspective, this study contributes to existing knowledge and Indian scholarship concerning eWOM through social media as the study provides a greater understanding of user-generated content on YouTube and its influence on the purchase intentions of consumers. Unlike the previous studies, this study was not concerned with vlogs related to beauty products only. Rather it explored other kinds of vlogs also. The findings of the study supported the theories used in this research: Theory of reasoned action and Social learning theory as the YouTube vloggers (Social media agents) are found to exert a positive influence on the purchase intentions of consumers. The conceptual model adopted in this study explored the mediation role of source credibility of YouTube vloggers for influencing consumers' purchase intentions.

\section{REFERENCES}

Ananda, A. F., \& Wandebori, H. (2016). The impact of drugstore makeup product reviews by beauty vlogger on YouTube towards purchase intention by undergraduate students in Indonesia. International Conference on Ethics of Business, Economics, and Social Science, 264-273.

Anderson, J. C., \& Gerbing, D. W. (1988). Structural equation modeling in practice: A review and recommended two-step approach. Psychological bulletin, 103(3), 411-423.

Bais, S. S., Murthy, A., Roy, T., \& Mehendale, S. (2018). Impact of electronic word-of-mouth on brand image and purchase intention: a methodological and thematic review. Asian Journal of Management, 9(1), 774-778.

Baker, M. J., \& Churchill G. A. Jr. (1977). The impact of physically attractive models on advertising evaluations. Journal of Marketing Research, 14(4), 538-555.

Bandura, A., \& Walters, R. H. (1963). Social learning and personality development.

Bianchi, S. (2016). Why Bloggers are more influential than celebrities in the Beauty Industry. Buzzstream.com. Accessed on November 1,2019

Bouhlel, O., Mzoughi, N., Ghachem, M. S., \& Negra, A. (2010). Online Purchase Intention, understanding the blogosphere effect. International Journal of e-Business Management, 4(2), 37-51.

Burgess, S., Sellitto, C., Cox, C., \& Buultjens, J. (2009). User-generated content (UGC) in tourism: benefits and concerns of online consumers. 17th European Conference on Information Systems. Verona.

Camahort, E. (2016). The 2011 Social Media Matters Study: Everyone is an early adopter... are you. Retrieved March, 12(2019), 5233-5251.

Chahal, M. (2016). Four trends that will shape media in 2016. [online] Marketing Week. Accessed on October 20, 2019

Cheung, M. Y., Luo, C., Sia, C. L. \& Chen, H. (2009). Credibility of electronic word-of-mouth: informational and normative determinants of on-line consumer recommendations. International Journal of Electronic Commerce, 13(4), 9-38.

Chu, S. C., \& Kamal S. (2008). The effect of perceived blogger credibility and argument quality on message elaboration and brand attitudes. Journal of Interactive Advertising. 8(2), 26-37.

Coyle, J. R., \& Thorson. E. (2001). The effects of progressive levels of interactivity and vividness in web marketing sites. Journal of Advertising, 30(3), 65-77. 
Cramer, D., \& Howitt, D. (2004). The sage dictionary of statistics: a practical resource for students in the social sciences. Thousand Oaks: Sage.

Davis, F. D. (1986). A technology acceptance model for empirically testing new end-user information systems: Theory and Results. (Ph.D. Dissertation). MIT Sloan School of Management, USA.

Deighton, J., \& Schindler, R. M. (1988). Can advertising influence experience?. Psychology \& Marketing, 5(2), 103-115.

Ding, L., Velicer, W. F., \& Harlow, L. L. (1995). Effects of estimation methods, number of indicators per factor, and improper solutions on structural equation modeling fit indices. Structural Equation Modeling: A Multidisciplinary Journal, 2(2), 119-143.

Djafarova, E., \& Rushworth, C. (2017). Exploring the credibility of online celebrities' Instagram profiles in influencing the purchase decisions of young female users. Computers in Human Behavior, 68, 1-7.

Erkan, I., \& Evans, C. (2016). The influence of e-Word of mouth in social media on consumers' purchase intentions: An extended approach to information adoption. Computers in Human Behavior, 61, 47-55.

Euijin, K., \& Tadisina, S. (2007). A model of consumers' trust in e-businesses: micro-level interparty trust formation. Journal of Computer Information System, 48(1), 88-104.

Fred, S. (2015). Examining Endorsement and Viewership Effects on the Source Credibility of YouTubers. Master's Thesis, University of South Florida, USA.

Freeman, K. S., \& Spyridakis, J. H. (2004). An examination of factors that affect the credibility of online health information. Technical Communication, 51(2), 239-263.

Hautz, J., Füller, J., Hutter, K., \& Thürridl, C. (2014). Let users generate your video ads? The impact of video source and quality on consumers' perceptions and intended behaviors. Journal of Interactive Marketing, 28(1), 1-15.

Haven, B., Charlene, Li., \& McHarg, T. (2007). Leveraging user-generated content. Cambridge, MA: Forrester Research, Inc.

Hayes, A. F. (2013). Introduction to mediation, moderation, and conditional process analysis: A regression-based approach. Guilford Press.

Hill, S. R., Troshani, I., \& Chandrasekar, D. (2017). Signaling effects of vlogger popularity on online consumers. Journal of Computer Information Systems. 1-9.

Hsu, C. L., Chuan-Chuan Lin, J., \& Chiang, H. S. (2013). The effects of blogger recommendations on customers' online shopping intentions. Internet Research, 23(1), 69-88.

Hsu, H. Y., \& Tsou, H. T. (2011). Understanding customer experiences in online blog environments. International Journal of Information Management, 31(6), 510-523.

Jannat, S. (2018). Influence of video bloggers on purchase intention of beauty products. A thesis submitted to the Department of Marketing, Events \& Tourism, University of Greenwich.

Jin, X. L., Cheung, C. M., Lee, M. K., \& Chen, H. P. (2009). How to keep members using the information in a computer-supported social network. Computers in Human Behavior, 25(5), 1172-1181.

Johnson, T. J., Kaye, B. K., Bichard, S. L., \& Wong, W. J. (2008). Every Blog has its day: politically-interested internet users' perceptions of blog credibility. Journal of Computer-Mediated Communication, 13, 100-122.

Joseph, W. B. (1982). The credibility of physically attractive communicators: A review. Journal of Advertising, 11(3), 15-24.

Kahle, L. R., \& Homer, P. M. (1985). Physical attractiveness of the celebrity endorser: a social adaptation perspective. Journal of Consumer Research, 11(5), 954-961.

King, M. M., \& Multon, K. D., (1996). The effects of television role models on the career aspirations of African American junior high school students. Journal of Career Development, 23(2), 111-125.

Lee, J. E., \& Watkins, B. (2016). YouTube vloggers' influence on consumer luxury brand perceptions and intentions. Journal of Business Research, 69(12), 5753-5760. 
Levin, I. P., \& Gaeth, G. J. (1988). How consumers are affected by the framing of attribute information before and after consuming the product. Journal of consumer research, 15(3), 374-378.

Lu, L. C., Chang, W. P., \& Chang, H. H. (2014). Consumer attitudes toward blogger's sponsored recommendations and purchase intention: The effect of sponsorship type, product type, and brand awareness. Computers in Human Behavior, 34, 258-266.

Luthie, C. (2004). Characteristics of Innovating Users in a Consumer Goods Field: An Empirical Study of SportRelated Product Consumers. Technovation, 24(9), 683-695.

Makgosa, R. (2010). The influence of vicarious role models on purchase intentions of Botswana teenagers. Young Consumers, 11(4) 307-319.

Mangold, W. G., \& Faulds, D. J. (2009). Social media: The new hybrid element of the promotion mix. Business horizons, 52(4), 357-365.

Martin, C. A., \& Bush, A. J., (2000). Do role models influence teenagers' purchase intentions and behavior?. Journal of Consumer Marketing, 17(5), 441-453.

McCroskey, J. (1966). Scales for the measurement of ethos. Speech Monographs. 33(1), 65-72.

Mir, I. A., \& Rehman, K. U. (2013). Factors affecting consumer attitudes and intentions toward user-generated product content on YouTube. Management Marketing. 8(4), 637-654.

Nugraha, A., \& Setyanto, R. P. (2018). The effects of vlogger credibility as marketing media on brand awareness to customer purchase intention. Journal of research in management, 1(2).

OECD (2007). Working party on the information economy.

Ohanian, R. (1990) Construction and validation of a scale to measure celebrity endorsers' perceived expertise, trustworthiness, and attractiveness. Journal of Advertising. 19(3), 39-52.

Ohanian, R. (1991). The impact of celebrity spokepersons' perceived image on consumers' intention to purchase. Journal of Advertising Research, 31(1), 46-54.

Petrick, J. F. (2002). Experience use history as a segmentation tool to examine golf travellers' satisfaction, perceived value and repurchase intentions. Journal of Vacation Marketing, 8(4), 332-342.

Pixability (2014). How YouTube is Radically Transforming the Beauty Industry and What That Meansfor Brands. Pixability.com. Accessed on October, 27, 2019

Pixability (2015) Beauty on YouTube: How YouTube is Radically Transforming the Beauty Industry and What That Means for Brands. Pixability.com. Accessed on October, 27, 2019

Pornpitakpan, C. (2003). Validation of the celebrity endorsers' credibility scale: Evidence from Asians. Journal of Marketing Management, 19(1-2), 179-195.

Rahmi, Y., Sekarasih, L., \& Sjabadhyni, B. (2017). The Influence of Beauty Vlog on Perceived Source Credibility and Purchase. Makara Hubs-Asia, 21(1), 13-23.

Saxena, A. (2011). Blogs and Their Impact on Purchase Intention: A Structural Equation Modelling Approach. Paradigm, 15(1\&2), 102-110.

See-To, E. W. K., \& Ho, K. K. W. (2014). Value co-creation and purchase intention in social network sites: the role of electronic word-of-mouth and trust-a-theoretical analysis. Computers in human behavior, 31(1), 182-189.

Tabachnick, B. G., \& Fidell, L. S. (2001). Cleaning up your act: Screening data prior to analysis. Using multivariate statistics, 5, 61-116.

Taylor, S. A., \& Baker, T. L. (1994). An assessment of the relationship between service quality and customer satisfaction in the formation of consumers' purchase intentions. Journal of retailing, 70(2), 163-178.

Tinsley, H. E., \& Tinsley, D. J. (1987). Uses of factor analysis in counseling psychology research. Journal of counseling psychology, 34(4), 414.

Wang, X., Yu, C., \& Wei, Y. (2012). Social media peer communication and impacts on purchase intentions: A consumer socialization framework. Journal of Interactive Marketing, 26(4), 198-208.

Wiley, D. (2014). Why brands should turn to bloggers instead of celebrity spokespeople 
Wilson, E., \& Sherrell, D. (1993). Source effects in communication and persuasion research: A meta-analysis of effect size. Journal of the academy of marketing science, 21(2), 101-112.

Yüksel, H. F. (2016). Factors affecting purchase intention in YouTube videos. The Journal of Knowledge Economy \& Knowledge Management, 11(2), 33-47. 
